\title{
PERANCANGAN MOTIF SATWA ENDEMIK INDONESIA PADA PRODUK FASHION SEBAGAI GERAKAN KEPEDULIAN SATWA MELALUI GAYA HIDUP
}

\author{
Belinda Carlita Sari \\ Program Studi Desain Komunikasi Visual, Universitas Ma Chung \\ Email : $\underline{31410019 @ \text { student.machung.ac.id }}$
}

\begin{abstract}
Abstrak
Indonesia menjadi negara dengan peringkat keenam dalam hal kepunahan biodiversitas alamnya termasuk satwa - satwa endemik yang hanya bisa ditemukan di Indonesia. Hal tersebut dikarenakan banyaknya ekploitasi dan kurangnya rasa peduli masyarakat terhadap keberadaan satwa endemik tersebut. Tujuan dirancang motif dengan mengangkat tema satwa endemik ini adalah sebagai suatu gerakan kepedulian satwa khususnya satwa endemik melalui gaya hidup yaitu dengan berpenampilan atau menggunakan produk fashion, seperti kaos, topi, sandal, sepatu dan tas. Metode yang digunakan dalam perancangan ini pertama-tama dengan pengumpulan data dengan mencari berbagai referensi desain motif satwa dan penerapannya, kemudian yang kedua menganalisis data dan mendapatkan hasil visualisasi desain. Hasil dari rancangan ini berupa 14 motif satwa endemik Indonesia yang berupa motif tanpa batas yang dapat diaplikasikan terutama pada media yang dapat dicetak dan dibentuk menjadi produk fashion seperti kaos, topi, tas, sepatu, sandal, masker dan case hp. Dari hasil perancangan ini diharapkan produk fashion yang dihasilkan dapat digunakan sehari hari, dengan demikian maka masyarakat akan lebih mengenal, lebih peduli akan kelestarian hewan edemik Indonesia.
\end{abstract}

Kata kunci: satwa endemik Indonesia, motif, motif satwa, fashion, gaya hidup

\begin{abstract}
Indonesia is the country with the sixth rank in terms of the extinction of its natural biodiversity, including endemic animals that can only be found in Indonesia. This is due to the large number of exploitations and the lack of public care for the existence of these endemic animals. The purpose of designing this pattern with the theme of endemic animals is as a movement for animal care, especially endemic animals through a lifestyle by dressing or using fashion products, such as $t$-shirts, hats, sandals, shoes and bags. The method used in this design is firstly by collecting data by looking for various references to animal pattern designs and their application, secondly analyzing the data and getting the results of design visualization. The results of this design are 14 Indonesian endemic animal pattern in the form of seamless pattern that can be applied especially to media that can be printed and formed into fashion products such as t-shirts, hats, bags, shoes, sandals, masks and cellphone cases. From the results of this design, it is expected that the fashion products produced can be used daily, thus the public will be more familiar with, more concerned about the preservation of Indonesia's endemic animals.
\end{abstract}

Keywords: Indonesian endemic animals, pattern, animal pattern, fashion, life style

\section{PENDAHULUAN}

Indonesia merupakan negara yang memiliki keanekaragaman hayati disebut juga biodiversitas daratan tertinggi kedua setelah Brazil. Namun, jika digabungkan dengan biodiversitas lautan, Indonesia menjadi peringkat satu terkaya akan keanekaragaman hayatinya berdasarkan National Geographic Indonesia (2019). Biodiversitas atau keanekaragaman hayati adalah keragaman organisme yang menunjukkan keseluruhan atau totalis variasi gen, jenis, dan ekosistem pada suatu daerah. Keseluruhan dari gen, jenis dan ekosistem merupakan dasar dari kehidupan dibumi, oleh karena itu melihat pentingnya keanekaragaman hayati bagi kehidupan maka keanekaragaman hayati perlu dipelajari dan dilestarikan, Wilsa, Hamida dan Devi (2015). Faktor- faktor yang menyebabkan Indonesia memiliki biodiversitas yang tinggi adalah bentang alam Indonesia, terbentang dari Benua Asia hingga Australia, antara Samudera Pasifik dan Samudera Hindia, jumlah pulau yang banyak, lautan yang luas dan iklim yang tropis.

Menurut Profauna, diperkirakan sebanyak 300.000 jenis satwa liar atau sekitar $17 \%$ satwa didunia ada di Indonesia walaupun luas Indonesia hanya 1,3\% dari luas muka bumi. Indonesia juga menjadi habitat bagi satwasatwa endemik, yaitu satwa yang hanya dapat kita temukan di Indonesia. Di Indonesia terdapat mamalia endemik sebanyak 259 jenis, burung sebanyak 384 jenis dan ampibi sebanyak 173 jenis, International Union for Conservation of Nature and Natural Resources atau disingkat IUCN (2013). Keberadaan satwa endemik sangatlah penting, karena jika punah di Indonesia maka artinya satwa tersebut juga punah dari dunia. Sangat disayangkan, Indonesia juga menjadi negara peringkat enam dengan kepunahan biodiversitas alam terbanyak, menurut Deputi Bidang Ilmu Pengetahuan dan Hayati di LIPI, Prof, Enny Sudarmonowati. Berdasarkan data Red List IUCN (2013), jumlah satwa yang tercatat sebanyak 5734 jenis dan yang punah sudah ada dua jenis dan yang berstatus terancam ( critical ) sebanyak 69 jenis, berstatus genting ( endangered ) 197 jenis dan berstatus rawan sebanyak 536 jenis. Di dalam bukunya yang berjudul " Kekinian Keanekaragaman Hayati Indonesia 2014, LIPI" ditetapkan 14 jenis satwa prioritas yang menjadi sorotan utama konservasi dan perlindungan. Hal-hal yang meyebabkan kepunahan terjadi di Indonesia antara lain berkurang dan rusaknya habitat satwa serta eksploitasi dan perdagangan satwa. Tidak lain hal ini dikarenakan sifat manusia yang destruktif seringkali menjadi penyebab hilangnya habitat asli suatu 
makhluk dan menyebabkan pernurunan populasi. Contohnya, keinginan manusia untuk memperluas lahan entah itu untuk pemukiman, pembangunan aset, pertanian dengan cara menggunduli dan membakar hutan yang merupakan habitat banyak makhluk hidup. Maraknya pembalakan liar menggunduli hutan tersebut membuat satwa sulit mencari makan untuk bertahan hidup dan berkembang biak, akibatnya banyak satwa mulai punah dan masuk ke dalam hewan yang dilindungi. Selain hutan, perburuan liar juga kerap terjadi di Indonesia lagi-lagi disebabkan oleh sifat tamak manusia yang menyebabkan semakin menurunnya populasi hewan dilindungi di Indonesia.

Melihat dari fenomena yang ada, perlu adanya upayaupaya konservasi untuk melestarikan satwa yang terancam dan juga perlu adaya edukasi mengenai pentingya menjaga dan ikut melestarikan satwa. Upayaupaya yang sudah dilakukan pemerintah untuk melestarikan satwa-satwa khususnya yang menjadi jenisjenis prioritas adalah dengan melakukan konservasi insitu dan ex-situ, antara lain, cagar alam, suaka margasatwa, taman nasional, hutan lindung, kebun binatang, dan taman safari. Namun upaya perlindungan satwa di Indonesia cenderung belum memberikan dampak yang sangat nyata, banyak masyarakat yang masih bergantung pada kondisi alam dengan tingkat pendapatan dan pendidikan rendah dan memandang satwa liar masih dapat dipergunakan sebagai sumber keuangan dalam memenuhi kebutuhan hidup LIPI (2014). Upaya lain yang kedepannya dilakukan adalah dengan menanamkan pemahaman ilmu pengetahuan hayati dan memberikan sosialisasi edukasi kepada masyarakat mengenai pentingya ikut menjaga dan melestarikan satwa endemik Indonesia.

Alternatif lain sebagai upaya untuk menjaga dan melestarikan satwa Indonesia adalah dengan membangun sebuah tren gaya hidup dalam masyarakat. Menurut KBBI, gaya hidup atau life style dapat diartikan sebagai pola tingkah laku sehari-hari manusia. Dalam masyarakat modern, gaya hidup (lifestyle) membantu mendefinisikan mengenai sikap, nilai-nilai, kekayaan, serta posisi sosial seseorang (Chaney, 2004). Gaya hidup meliputi karakter, tata cara, apa yang mereka konsumsi dan gunakan dalam kehidupan sehari-hari. Salah satu yang tidak dapat lepas dari gaya hidup adalah fashion. Fashion adalah benda-benda yang kita gunakan dalam kehidupan sehari-hari seperti baju, celana, tas, topi, aksesori, sepatu, dll. Benda-benda seperti itu dikenakan bukanlah untuk sekedar penutup tubuh dan hiasan, melainkan menjadi alat komunikasi untuk menyampaikan identitas pribadi. Di dalam masyarakat, di mana persoalan gaya adalah sesuatu yang penting (atau malah gaya merupakan segalanya), semua manusia adalah performer. Contoh fashion sebagai gaya hidup yang memerankan kepribadian seseorang antara lain penggunakan pakaian batik, sebagai performer menggunakan batik maka akan timbul asumsi bahwa pribadi tersebut ikut melestarikan batik sebagai budaya Indonesia, ikut mengharumkan nama Indonesia, hal ini juga berlaku saat kaum perempuan menggunakan kebaya. Yang kedua yaitu produk clothing yang dicetuskan oleh VJ Daniel Mananta yang diberi nama "DAMN! I LOVE
INDONESIA". Sesuai dengan misinya yaitu menginspirasi anak muda Indonesia agar semakin mencintai budaya dan sejarah Indonesia dalam bautan gaya hidup urban. Ketika orang mengenakan brand tersebut maka akan menaikan rasa patriotism dalam dirinya, begitu pula bagi penikmat fashion akan berasumsi bahwa dia mencintai dan bangga akan negerinya Indonesia. Tak hanya bertarget masyarakat di Indonesia, target market pun tertuju pada konsumenasing. Produk tersebut pernah digunakan oleh musisi Maroon 5, Adam Lavine di dalam konsernya, hal ini tidak dipungkiri bahwa konsumen asing bisa ikut mencintai budaya Indonesia lewat sebuah fashion gaya hidup.

Gaya hidup terutama fashion berperan penting dalam kehidupan sehari-hari manusia, hal ini diharapkan gaya hidup menjadi sebuah strategi efektif untuk membantu menjaga dan melestarikan satwa di Indonesia. Salah satu hal yang melekat pada fashion adalah sebuah motif. Motif menurut Jackie (2010) merupakan sarana komunikasi non-verbal yang kuat yang digunakan untuk membedakan, menyamar, memperingatkan dan memikat. Ditandai dengan irama, keseimbangan dan proporsi. Melalui motif satwa endemik Indonesia yang kemudiakan akan diaplikasian di produk fashion diharapkan dapat menjadi sosialiasi gerakan kepedulian satwa. Melalui Tugas Akhir ini, penulis akan melakukan perancangan motif yang bertemakan satwa Indonesia dengan tujuan untuk meningkatkan kesadaran masyarakat tentang pelestarian dan pemeliharaan satwa endemik Indonesia. Melalui sebuah motif ini, diharapkan masyarakat menjadi tahu akan pentingnya menjaga dan melestarikan satwa, masyarakat menjadi bangga akan biodiversitas negrinya dan peduli akan satwa-satwa di Indonesia. Perancangan motif ini juga tak lepas dari prinsip-prinsip estetika dan Desain Komunikasi Visual sebagai penunjang proses perancangan. Motif akan kemudian diaplikasikan pada produk fashion seperti baju, jaket, topi, sepatu, tote bag, dll.

\section{TINJAUAN PUSTAKA}

Dalam perancangan ini, diperlukan beberapa tinjauan pustaka terhadap jurnal penelitian yang telah dilakukan. Hal ini untuk meningkatkan pemahaman kita tentang topik yang sedang digeluti. Selain itu tinjauan pustaka juga diperlukan untuk mengidentifikasi teknik, tata cara perancangan, alur dan metode yang relevan dengan topik penelitian. Berikut beberapa tinjauan pustaka yang akan menjadi panduan dalam perancangan ini. Yang pertama jurnal penelitian terdahulu Tanamal, Natadjaja dan Hosana (2016) dengan judul Perancangan Motif Ikan Cupang Hias pada Tekstil Beserta Brandingnya. Kedua, Ayu dan Putri (2019) dalam judul Kajian Perancangan Motif Kopi Cengkeh pada Batik Malangan dengan Teknik Shape Grammar, ketiga jurnal Tanzil (2018) dalam Penerapan Inspirasi Fauna dan Flora Sumatera Terhadap Perancangan Motif Tekstil Kontemporer. Sebagai buku referensi penulis menggunakan buku Desain Komunikasi Visual, Dasar-Dasar Panduan untuk Pemula karya Lia Anggraini dan Kirana Nathalia, serta Buku Kekinian Keanekaragaman Hayati Indonesia 2014 
yang diterbitkan oleh LIPI (Lembaga Ilmu Pengetahuan Indonesia). Selain itu juga dibutuhkan kajian sumber ide perancangan yang sangat membantu penulis untuk merancangan sebuah motif diambil dari beberapa referensi karya seperti karya Martha Puri Natasande dalam laman Instagram @idekuhandmade, laman Instagram@mellow.sk, referensi pengaplikasian motif pada produk fashion dari laman Instagram @ callathelabel dan referensi penyusunan motif dari laman Instagram @Christinedecarvalho.

\section{METODE PENELITIAN}

Metode yang digunakan adalah metode deskriptif kualitatif, yang diawali dengan menentukan later belakang permasalahan dan kemudian mengindetifikasi melalui proses obeservasi pada target market. Proses observasi dilakukan dengan mengamati kebiasaan, tingkah laku, serta gaya hidup dan bagaimana cara mereka berpakaian serta memilih gaya fashion melalui media sosial, seperti Instagram, Tik-Tok dan Website. Selain Observasi juga dilakukan studi pustaka melalui jurnal, penelitian terlebih dahulu dan pencarian data online di internet. Setelah itu data akan dianalisis secara deskriptif berdasarkan objek perancangan dan permasalahan yang dihadapi kemudian akan dihasilkan strategi perancangan. Data-data yang digunakan dalam proses perancangan kemudian akan divisualisasikan kedalam beberapa alternatif pada produk fashion. Dari beberapa alternatif desain tersebut akan dilakukan proses seleksi terhadap desain yang sesuai dan akan di buat hasil akhir atau final serta pengaplikasinannya pada produk nyata.

\section{HASIL DAN PEMBAHASAN}

Analisis data dibagi menjadi 14 bagian yaitu analisis dari masing - masing satwa yang akan diilustrasikan menjadi sebuah motif. Analisis data diperoleh dari studi Pustaka dari jurnal ataupun buku dan juga pencarian data di internet. Berdasarkan data-data yang diperoleh nantinya akan dianalisis terlebih dahulu kemudian digunakan sebagai bahan pembuatan motif.
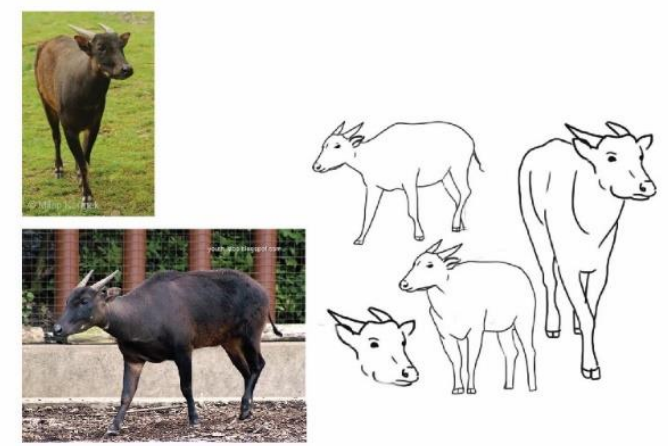

Gambar 1. Sketsa Anoa Cumbar. Doliuman Danulic
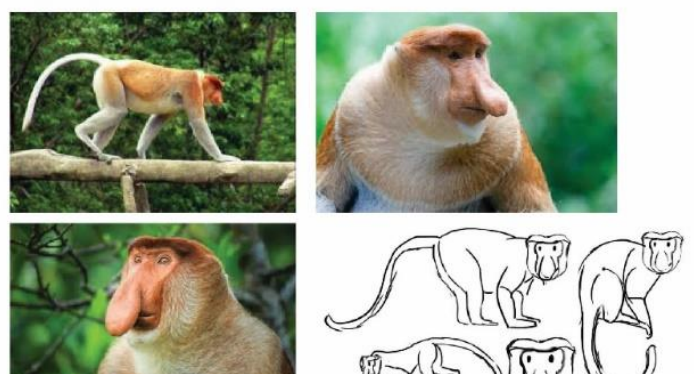

Gambar 2. Sketsa Bekantan

Sumber: Dokumen Penulis
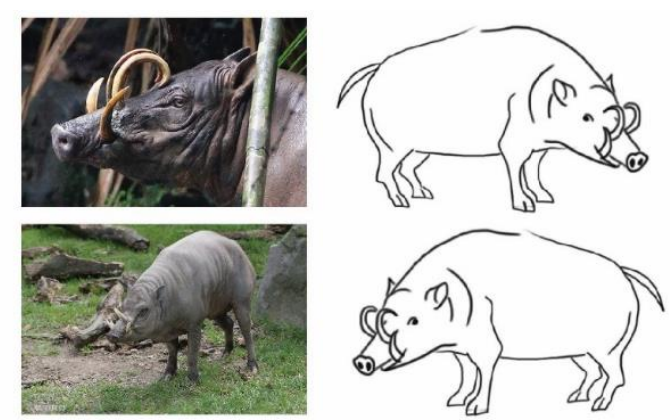

Gambar 3 Sketsa Babi Rusa

Sumber: Dokumen Penulis
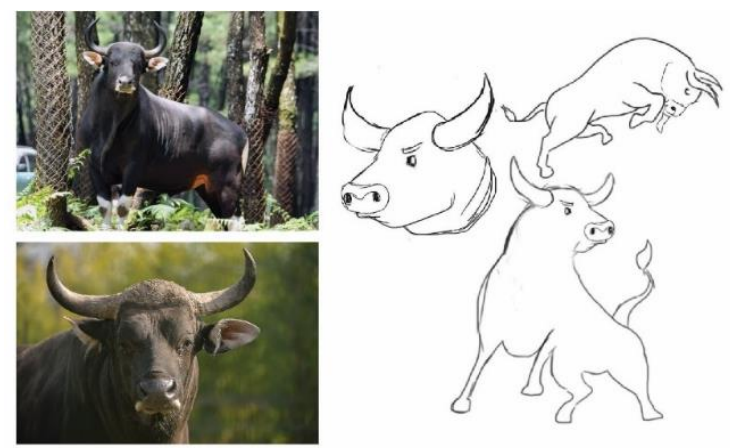

Gambar 4. Sketsa Banteng Sumber: Dokumen Penulis

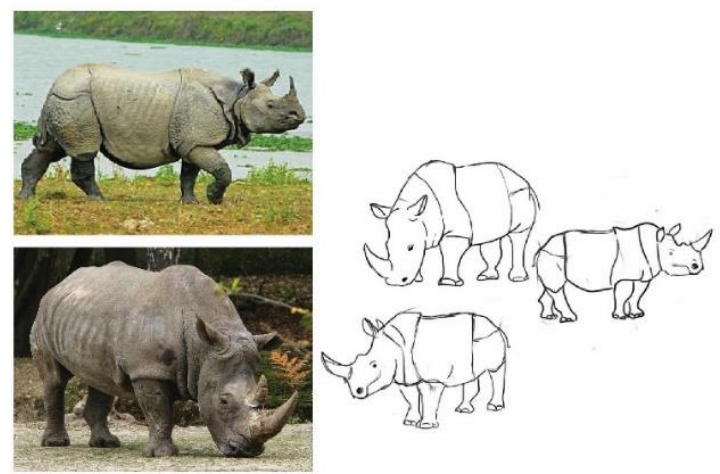

Gambar 5. Sketsa Badak Bercula Satu Sumber: Dokumen Penulis 

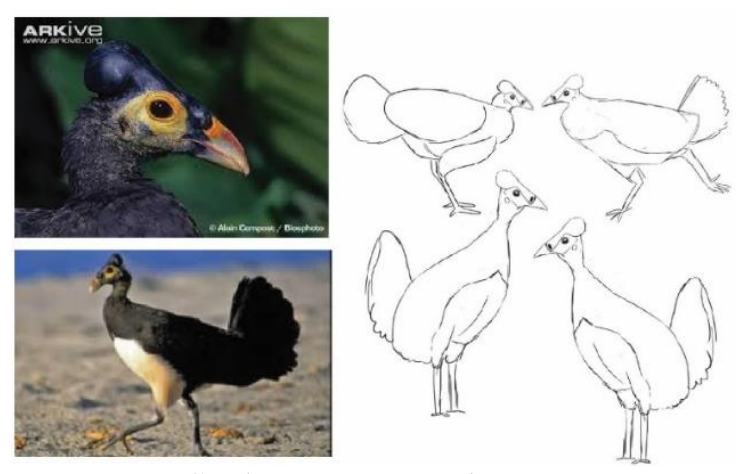

Gambar 6. Burung Maleo

Sumber: Dokumen Penulis
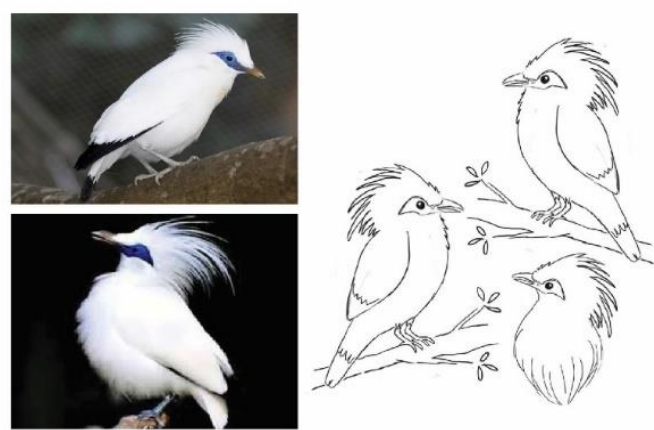

Gambar 7. Curik Bali Sumber: Dokumen Penulis

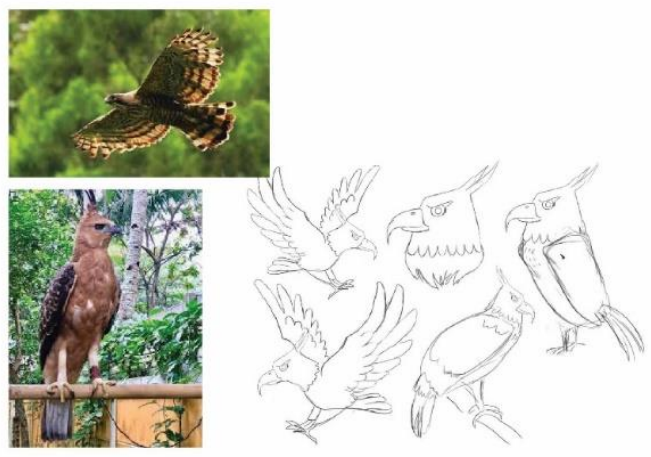

Gambar 8. Sketsa Elang Jawa

Sumber: Dokumen Penulis
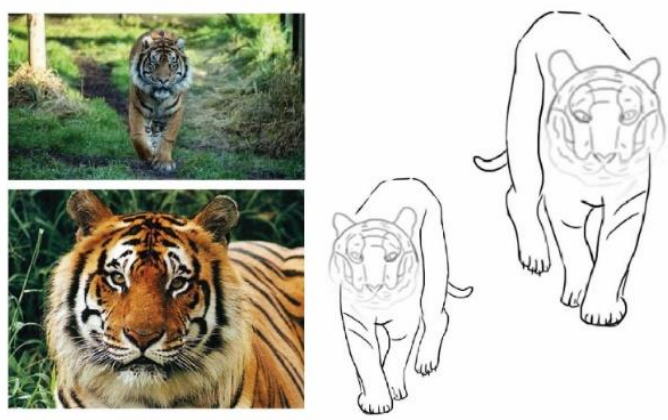

Gambar 9. Harimau Sumatera

Sumber: Dokumen Penulis

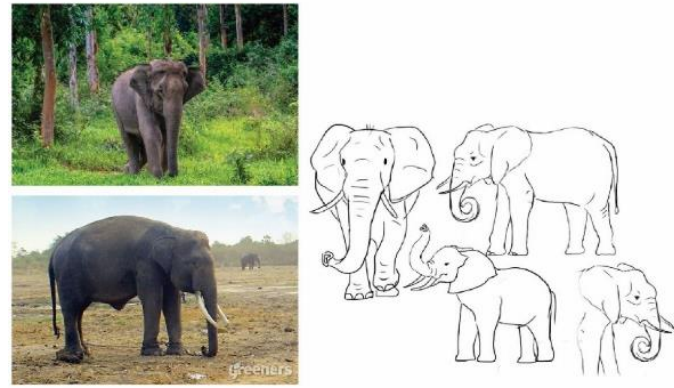

Gambar 10. Sketsa Gajah Sumatera Sumber: Dokumen Penulis
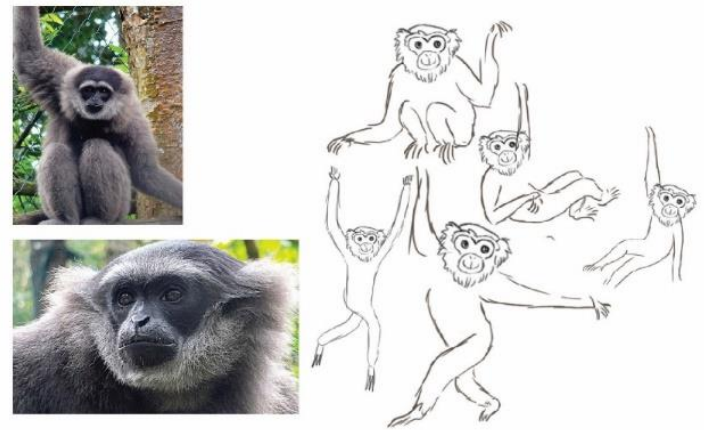

Gambar 11. Owa Jawa

Sumber: Dokumen Penulis

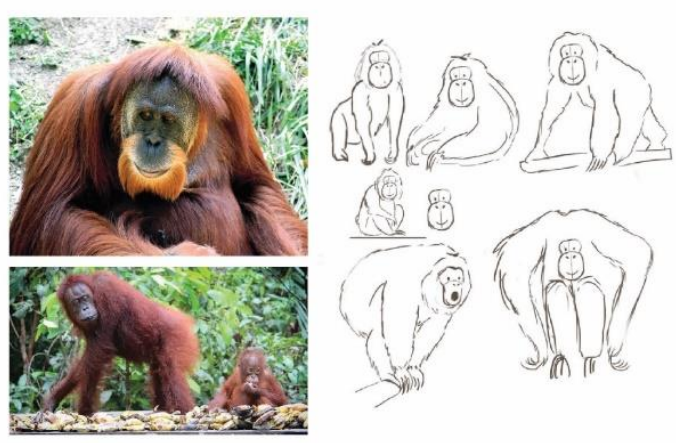

Gambar 12. Orang Utan Sumber: Dokumen Penulis
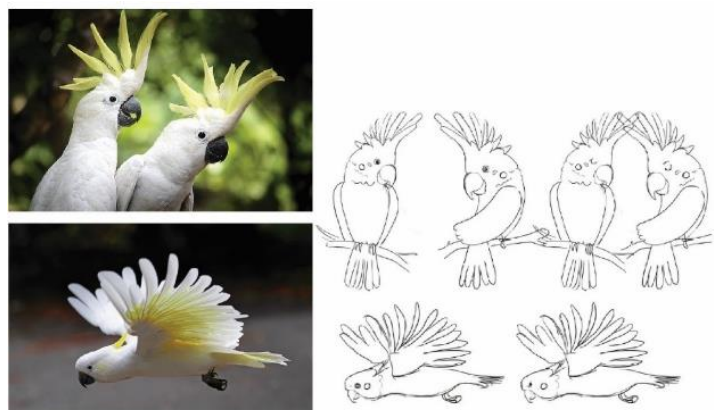

Gambar 13. Kakatua Jambul Kuning Sumber: Dokumen Penulis 


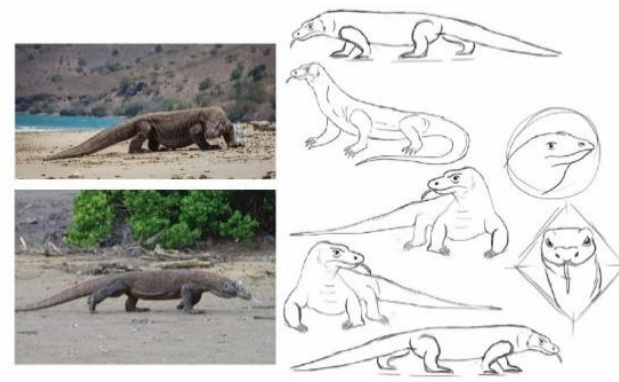

Gambar 14. Komodo

Sumber: Dokumen Penulis

Warna yang digunakan dalam perancangan motif satwa ini diambil berdasarkan iklim dari Indonesia yaitu Iklim Topis yang memiliki 2 musim yaitu musim hujan dan kemarau. Berikut merupakan color pallete yang digunakan dalam perancangan motif.
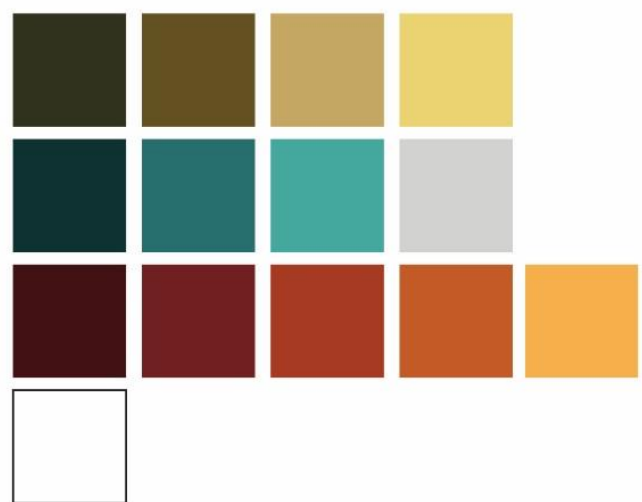

Gambar 15 Color Pallete

Sumber: Dokumen Penulis

Selain ilustrasi satwa, dibutuhkan pula elemen - elemen pendukung yang digunakan dalam perancangan motif satwa hal ini bertujuan agar motif terlihat lebih heterogen dan dekoratif. Elemen yang digunakan merupakan ilustrasi dari benda -benda alam seperti, pohon, dahan, ranting, daun, semak, rumput, batu, matahari dan burung. Berikut merupakan elemen-elemen yang digunakan dalam perancangan motif.

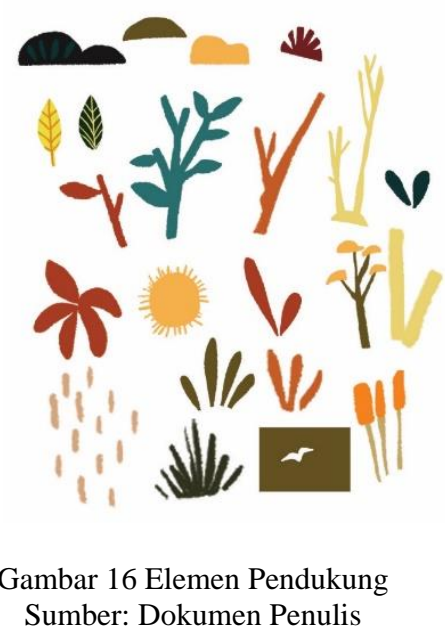

\section{Alat dan Bahan}

Dalam proses perancangan motif satwa ini diperlukan alat sebagai sarana dan prasaranan pengerjaan motif yaitu seperangkat laptop dan pen tablet. Sedangkan bahan yang dibutuhkan berupa data - data hasil pencarian yan digunakan sebagai acuan pembuatan illustrasi satwa

\section{HASIL VISUALISASI DESAIN}

Hasil dari perancangan ini berupa 14 motif satwa endemik Indonesia dimana satu satwa akan dijadikan satu motif yang kemudian diaplikasikan pada produk fashion. Berikut merupakan hasil dari perancangan motif satwa Endemik Indonesia.

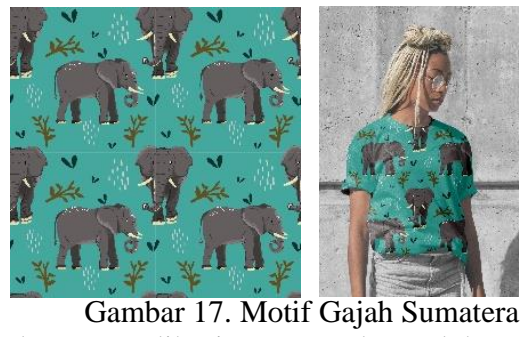

dan Pengaplikasiannya pada Produk Fashion. Sumber: Dokumen Penulis
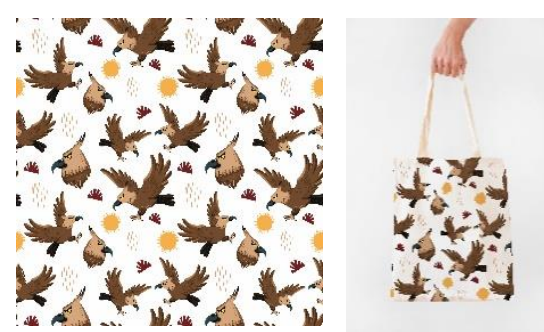

Gambar 18. Motif Elang Jawa

dan Pengaplikasiannya pada Produk Fashion. Sumber: Dokumen Penulis
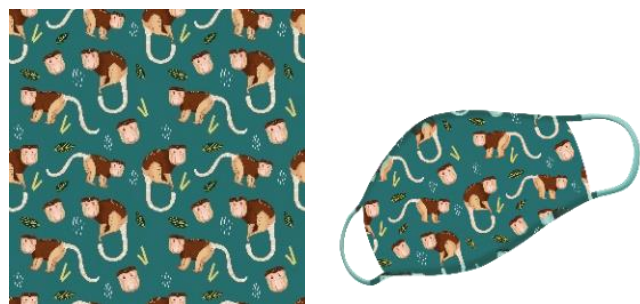

Gambar 19. Motif Bekantan

dan Pengaplikasiannya pada Produk Fashion. Sumber: Dokumen Penulis
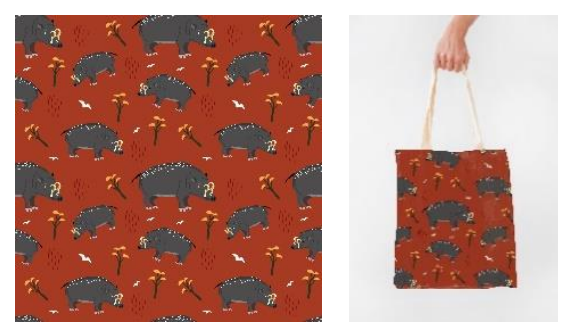

Gambar 20. Motif Babi Rusa dan Pengaplikasiannya pada Produk Fashion. 
Sumber: Dokumen Penulis

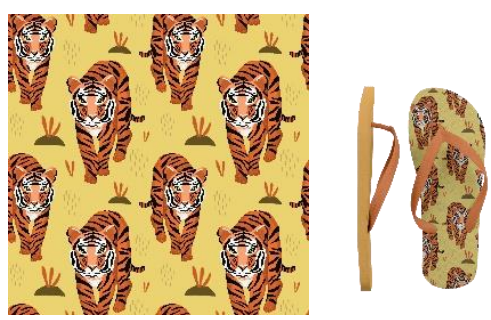

Gambar 21. Motif Harimau Sumatera dan Pengaplikasiannya pada Produk Fashion. Sumber: Dokumen Penulis
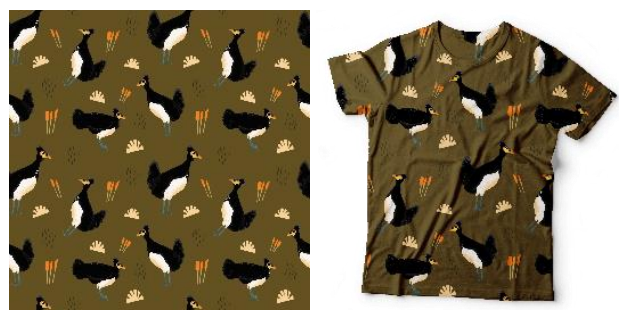

Gambar 22. Motif Maleo

dan Pengaplikasiannya pada Produk Fashion. Sumber: Dokumen Penulis
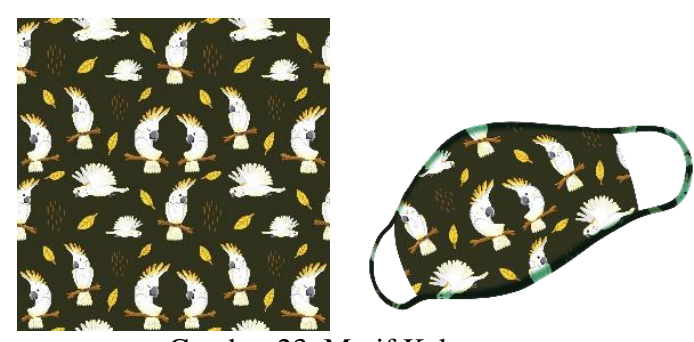

Gambar 23. Motif Kakatua

dan Pengaplikasiannya pada Produk Fashion. Sumber: Dokumen Penulis
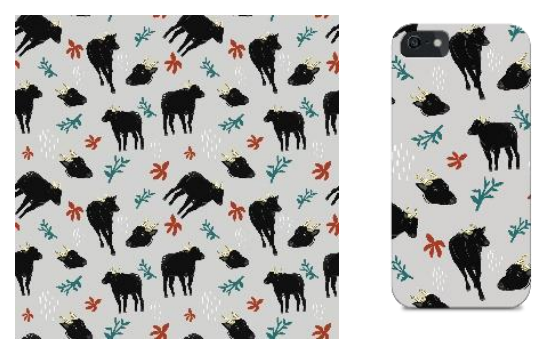

Gambar 24. Motif Anoa

dan Pengaplikasiannya pada Produk Fashion. Sumber: Dokumen Penulis

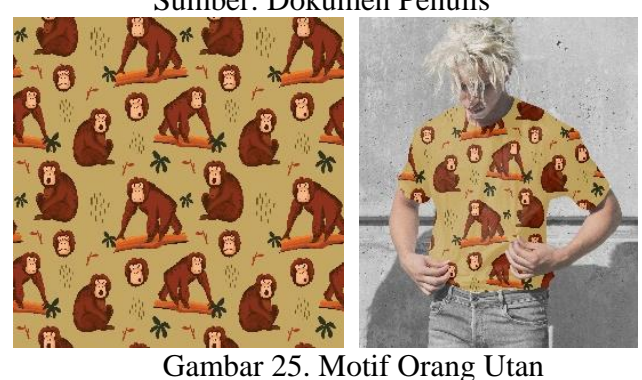

dan Pengaplikasiannya pada Produk Fashion.
Sumber: Dokumen Penulis

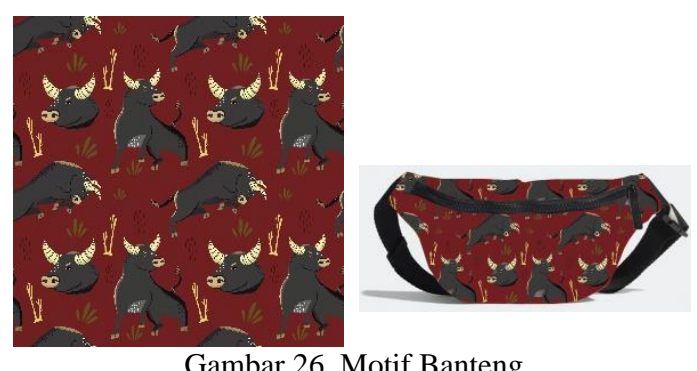

dan Pengaplikasiannya pada Produk Fashion. Sumber: Dokumen Penulis

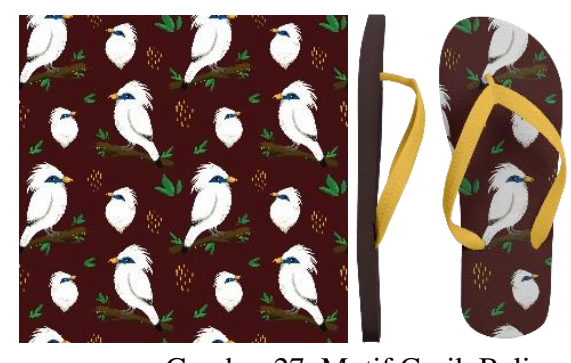

Gambar 27. Motif Curik Bali

dan Pengaplikasiannya pada Produk Fashion. Sumber: Dokumen Penulis

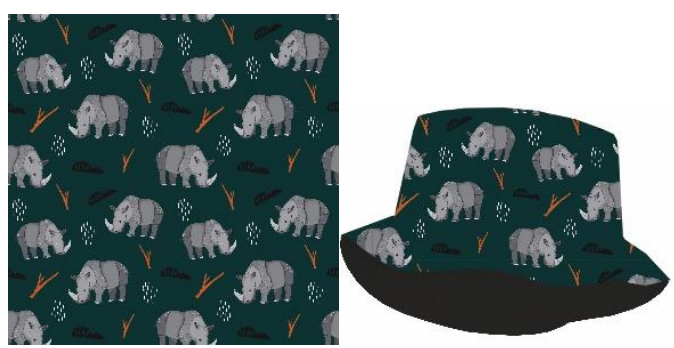

Gambar 28. Motif Badak Bercula Satu dan Pengaplikasiannya pada Produk Fashion. Sumber: Dokumen Penulis
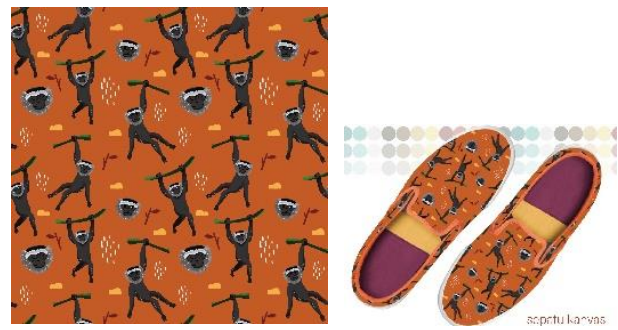

Gambar 29. Motif Owa Jawa

dan Pengaplikasiannya pada Produk Fashion. Sumber: Dokumen Penulis

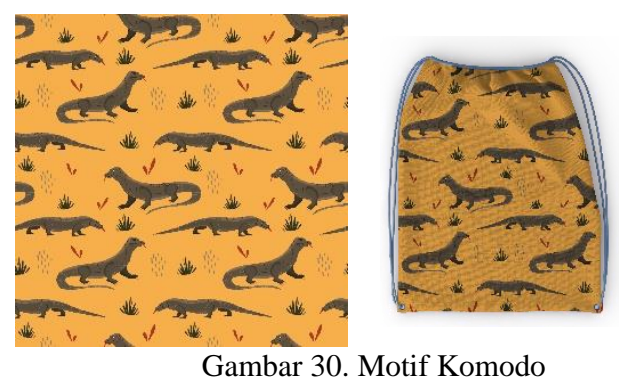

dan Pengaplikasiannya pada Produk Fashion. Sumber: Dokumen Penulis 


\section{KESIMPULAN DAN SARAN}

Indonesia merupakan negara yang memiliki keanekaragaman hayati disebut juga biodiversitas daratan tertinggi kedua setelah Brazil. Namun, jika digabungkan dengan biodiversitas lautan, Indonesia menjadi peringkat satu terkaya akan keanekaragaman hayatinya berdasarkan National Geographic Indonesia (2019). Berdasarkan data diatas maka penulis tertarik untuk mengangkat tema kepedulian satwa khususnya satwa endemik Indonesia. Ada 14 jenis satwa yang termasuk kedalam red list IUCN yaitu anoa, bekantan, owa jawa, orang utan, Komodo, banteng, harimau sumatera, gajah sumatera, curik bali, kakatua jambul kuning, burung maleo, babirusa, badak cula satu dan elang jawa. Berdasarkan data diatas penulis ingin melestarikan satwa yang terancam punah tersebut dengan cara mengaplikasikannya pada produk fashion. Produk fashion dipilih melalui observasi dengan mengamati kebiasaan, tingkah laku, serta gaya hidup, dan bagaimana cara berpakaian, serta memilih gaya fashion melalui media sosial, seperti instagram, tik-tok, dan website. Dengan demikian fashion yang dipilih akan sesuai dengan minat target pasar yang sudah ditentukan karena sesuai dengan tren terkini.

Sebagai Langkah awal, penulis membuat motif berupa 14 ilustrasi satwa tersebut yang kemudian akan diaplikasikan pada produk fashion. Produk - produk yang dihasilkan berupa scarf, baju, tote bag, tas serut, tas pinggang, topi, masker, sandal dan sepatu. Dari hasil perancangan ini diharapkan produk fashion yang dihasilkan dapat digunakan sehari-hari. Dengan demikian maka masyarakat akan lebih peduli akan kelestarian hewan endemik Indonesia. Saran bagi mahasiswa yang akan melakukan perancangan dengan tema yang serupa untuk lebih memperhatikan gaya fashion saat perancangan tersebut dilakukan. Hal tersebut wajib dilakukan agar dapat sesuai dengan minat target pasar saat itu. Serta sebisa mungkin mengangkat tema seputar kelestarian budaya Indonesia, seperti flora, folklore, budaya tradisonal Indonessia, dll.

\section{DAFTAR PUSTAKA}

Aaker, D. A. 1996, Building Strong Brands. The Free Press, New York

Ambrose, Gavin., dan Paul Harris. 2010, Design Thikning. AVA Publishing SA, Switzerland.

Anggraini, S.L dan Nathalia, K. 2014, Desain Komunikasi Visual, Dasar-Dasar Panduan untuk Pemula. Penerbit Nuansa Cendekia, Bandung, Indonesia.

Bowles, M. and Isaac, C. 2009, Digital Textile Design. Laurence King Publishing, London UK.

Chaney, David. 2004, Lifestyle Sebuah Pengantar Komprehensif, Jalasutra, Yogyakarta.

Clarke, C. 2011, Textile Design: Portfolio Series. Laurence King Publishing, London UK.

Kotler dan Keller. 2009, Manajemen Pemasaran. Erlangga, Jakarta.
Kusrianto,Adi. 2007, Pengantar Desain Komunikasi Visual ,Penerbit ANDI, Yogyakarta.

Rustan, Surianto. 2009, Mendesain Logo. PT Gramedia Pustaka Utama, Jakarta

Sunyoto, D. 2018, Konsep Dasar Riset Pemasaran dan Perilaku Konsumen. CAPS (Center for Academic Publishing Service), Yogyakarta

Tjiptono. 1995, Strategi Pemasaran. Andi Offset, Yogyakarta. 